\title{
Design of high-strength concrete beams subjected to small axial loads
}

\author{
A. K. H. Kwan, * S. L. Chau* and F. T. K. Au* \\ University of Hong Kong
}

\begin{abstract}
In the design of reinforced concrete beams, the effects of small axial loads (axial load $\leqslant 10 \%$ of axial capacity of concrete section) are often ignored or at most only nominally allowed for. Moreover, the existing guidelines given in the various design codes are applicable only to beams cast of normal-strength concrete and designers are left to themselves to decide what to do when high-strength concrete is used. In this study, the effects of small axial loads on the flexural strength and ductility of normal- and high-strength concrete beams have been investigated by complete moment-curvature analysis of beam sections cast of different grades of concrete and subjected to different levels of axial load. The results revealed that the application of a small axial load has the beneficial effect of increasing the flexural strength but also the adverse effect of decreasing the flexural ductility. Based on the numerical results, simple formulae for estimating the effects of small axial loads and guidelines for the design of normal-and high-strength concrete beams subjected to small axial loads have been developed.
\end{abstract}

\section{Notation}

$A_{\text {sc }} \quad$ area of compression steel reinforcement

$A_{\text {st }} \quad$ area of tension steel reinforcement

$b \quad$ breadth of beam section

$d \quad$ effective depth of beam section

$d_{1} \quad$ depth of compression reinforcement

$E_{\mathrm{s}} \quad$ elastic modulus of steel reinforcement

$f_{\mathrm{c}} \quad$ in situ uniaxial compressive strength of concrete

$f_{\text {cu }} \quad$ cube compressive strength of concrete

$f_{\mathrm{yc}} \quad$ yield strength of compression steel reinforcement

$f_{\mathrm{yt}} \quad$ yield strength of tension steel reinforcement

$h \quad$ total depth of beam section

$P \quad$ axial load applied to the geometric centre of beam section

$P_{\mathrm{b}} \quad$ axial load at balanced failure point

$P_{\mathrm{o}} \quad$ axial load giving maximum moment capacity

$\lambda \quad$ degree of reinforcement

$\lambda_{\max }$ maximum allowable degree of reinforcement

$\mu \quad$ curvature ductility factor

$\mu_{\min }$ minimum required curvature ductility factor

$\rho_{\mathrm{b}} \quad$ balanced steel ratio of section

\footnotetext{
* Department of Civil Engineering, The University of Hong Kong, Hong Kong, China.
}

(MCR 51448) Paper received 22 August 2005; accepted 6 January 2006.

$\begin{array}{ll}\rho_{\mathrm{bo}} & \text { balanced steel ratio of section without axial load } \\ & \text { and compression steel } \\ \rho_{\mathrm{c}} & \text { compression steel ratio }\left(\rho_{\mathrm{c}}=A_{\mathrm{sc}} / b d\right) \\ \rho_{\mathrm{t}} & \text { tension steel ratio }\left(\rho_{\mathrm{t}} A_{\mathrm{st}} / b d\right) \\ \phi_{\mathrm{u}} & \text { ultimate curvature of beam section } \\ \phi_{y} & \text { yield curvature of beam section }\end{array}$

\section{Introduction}

In the design of reinforced concrete beams, both flexural strength and ductility need to be considered. However, many engineers just concentrate on the provision of sufficient flexural strength to resist the ultimate loads, without paying much attention to flexural ductility. This is partly the result of lack of awareness of the importance of flexural ductility and partly the result of the difficulty of evaluating the flexural ductility of a given section or member. To ensure the provision of a certain minimum level of flexural ductility, most of the existing design codes impose maximum limits onto the tension steel ratio either directly or indirectly. For example, ACI $318-99^{1}$ imposes a direct limit to the tension steel ratio equal to 0.75 times the balance steel ratio. Later, ACI $318-02^{2}$ imposes an indirect limit to the tension steel ratio by requiring the net tensile strain in the tension steel to be not less than 0.004 when the concrete fails in compression. On the other hand, AS $3600-1994^{3}$ restricts the tension steel ratio by requiring the neutral axis depth to be not greater than 0.4 of the 
effective depth. Similarly, BS $8110: 1997^{4}$ restricts the tension steel ratio by requiring the neutral axis depth to be not greater than 0.5 of the effective depth.

As the application of a small axial load to a reinforced concrete beam would increase the flexural strength, it is generally assumed in the design codes that the effects of any axial load may be safely neglected, provided that the axial load is not too large. For instance, in ACI 318-99, ACI 318-02 and AS 36001994, the effects of axial load are ignored if the axial load is not greater than $0 \cdot 1 f_{\mathrm{c}}{ }^{\prime}$ times the gross-sectional area ( $f_{\mathrm{c}}^{\prime}$ is the cylinder strength of concrete), while in BS 8110:1997, the effects of axial load are ignored if the axial load is less than $0 \cdot 1 f_{\text {cu }}$ times the gross-sectional area ( $f_{\text {cu }}$ is the cube strength of concrete). However, experimental studies $^{5-7}$ have shown that the presence of axial load also has the adverse effect of causing significant reduction in flexural ductility. Therefore, in cases where ductility is critical, it may not be safe to ignore the effects of axial load.

Owing to the increasing height of tall buildings and span length of bridges, which demand higher-strength materials to be used, high-strength concrete (HSC) is gaining popularity in the construction industry. Despite its frequent use, most of the existing codes still do not cover HSC. As HSC is generally more brittle, the design of HSC members as per the existing codes that are applicable only to normal-strength concrete may result in an unacceptably low ductility level. The effects of using HSC on the flexural ductility of reinforced concrete members have been studied ${ }^{8,9}$ and a design method for ensuring the achievement of a minimum required ductility level has been developed. ${ }^{10}$ However, the combined effects of using HSC and application of a small axial load have not been studied so far. Since ductility might become critical when HSC is used, it is questionable whether the effects of a small axial load could be neglected in the design of a HSC beam.

In the study presented herein, a rigorous parametric study based on complete moment-curvature analysis has been carried out to evaluate the flexural strength and ductility of reinforced concrete beams cast of different grades of concrete and subjected to different levels of axial load. The aims of the study were to develop formulae for estimating directly the effects of a small axial load and to set up guidelines for the design of HSC beams subjected to small axial loads.

\section{Moment-curvature analysis}

In the analysis, the actual stress-strain curves of the constitutive materials, instead of the simplified stressstrain curves given in the design codes, are used. For the concrete, the stress-strain curve model developed by Attard and Setunge ${ }^{11}$ and Attard and Stewart ${ }^{12}$ is adopted. This model has been shown to be applicable to both normal- and high-strength concrete with uniax- ial compressive strength ranging from 20 to $130 \mathrm{MPa}$. For the steel reinforcement, the stress-strain relation is assumed to be linearly elastic perfectly plastic. Since strain reversal could occur in the steel reinforcement even with monotonic increase of curvature, the stressstrain curve is stress-path dependent and, for simplicity, the unloading path is taken to follow the slope of the initial elastic portion of the stress-strain curve.

Three basic assumptions have been made in the analysis: (a) plane sections remain plane after bending; (b) the tensile strength of concrete is negligible; and (c) there is no bond-slip between concrete and steel reinforcement. The axial load is applied at the geometric centre of the beam section right at the beginning before any curvature or moment is applied. The momentcurvature behaviour of the beam section is analysed by applying prescribed curvatures to the section incrementally starting from zero. At a prescribed curvature, the strain profile is evaluated based on an assumed concrete strain at the extreme compression fibre. From the strain profile evaluated, the stresses developed in the constitutive materials are determined from their respective stress-strain relations. Axial equilibrium is then checked and if necessary the assumed concrete strain at the extreme compression fibre is adjusted until the axial equilibrium condition is satisfied. After satisfying the axial equilibrium condition, the resisting moment is evaluated from the moment equilibrium condition. The above procedure is repeated until the resisting moment, after reaching the peak, has dropped to $50 \%$ of the peak moment. Other details of the analysis procedures may be found in references $8-10$.

Using the above analytical method, a parametric study on the complete moment-curvature behaviour of normal- and high-strength concrete beams subjected to different levels of axial load has been carried out. Fig. 1 shows the details of the beam sections analysed. The sections have the same dimensions of $b=300 \mathrm{~mm}, h=$ $600 \mathrm{~mm}, d=550 \mathrm{~mm}$ and $d_{1}=50 \mathrm{~mm}$. In order to cover both normal- and high-strength concrete, the concrete compressive strength $f_{\mathrm{c}}$ (to be more precise, the in situ uniaxial compressive strength, which is taken as the stress at the peak of the compressive stress-strain curve) is varied from 30 to $90 \mathrm{MPa}$. On the other hand, the steel reinforcement is assumed to have a constant elastic modulus of $E_{\mathrm{s}}=200 \mathrm{GPa}$ and constant tensile and compressive yield strengths of $f_{\mathrm{yt}}=f_{\mathrm{yc}}=460 \mathrm{MPa}$. Apart from the concrete grade, the other variables studied include the tension steel ratio, the compression steel ratio and the axial load level. The tension steel ratio $\rho_{\mathrm{t}}$ (defined by $\rho_{\mathrm{t}}=A_{\mathrm{st}} / b d$ ) is varied from 0.2 to 1.2 times the balanced steel ratio $\rho_{\text {bo }}$ of the section with no compression reinforcement and no axial load so as to cover both under- and over-reinforced sections, while the compression steel ratio $\rho_{\mathrm{c}}$ (defined by $\rho_{\mathrm{c}}=A_{\mathrm{sc}} / b d$ ) is varied from 0 to $1.5 \%$ to cover both singly and doubly reinforced sections. For the axial load level (defined in terms of $P\left(f_{\mathrm{c}} b d\right.$ ), it is varied from 0 to 0.5 . 


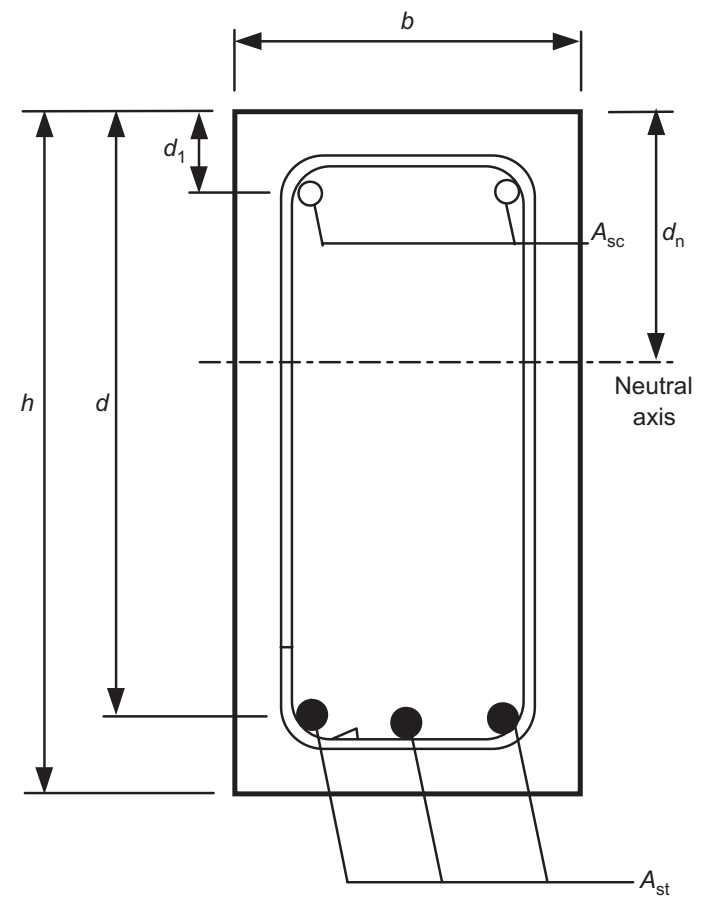

Fig. 1. Beam sections analysed

\section{Effects of small axial load}

Some selected moment-curvature curves showing the effects of axial load at different tension to balanced steel ratios of $\rho_{\mathrm{t}} / \rho_{\mathrm{bo}}=0.5$ and $\rho_{\mathrm{t}} / \rho_{\mathrm{bo}}=0.75$ for singly reinforced sections with concrete compressive strength $f_{\mathrm{c}}=30 \mathrm{MPa}$ and $f_{\mathrm{c}}=70 \mathrm{MPa}$ are presented in Figs 2 and 3 , respectively. From these moment-curvature curves, it is evident that in general at a relatively low axial load level, increasing the axial load would slightly increase the moment capacity but when the axial load level has become higher than a certain critical value, which is dependent on the tension to balanced steel ratio and concrete compressive strength, increasing the axial load would decrease the moment capacity. More importantly, regardless of the axial load level, increasing the axial load would always decrease the flexural ductility. Therefore, although a small axial load may have the beneficial effect of slightly increasing the moment capacity, it has at the same time the adverse effect of causing reduction in flexural ductility.

Comparing the moment-curvature curves of sections with $\rho_{\mathrm{t}} / \rho_{\text {bo }}=0.5$ in Figs 2(a) and 3(a) to those with $\rho_{\mathrm{t}} / \rho_{\text {bo }}=0.75$ in Figs 2 (b) and 3(b), it is seen that the increase in moment capacity with the axial load before the moment capacity drops when the axial load becomes too large, is smaller at a higher degree of reinforcement (i.e. at a higher value of $\rho_{\mathrm{t}} / \rho_{\mathrm{bo}}$ ). It is also seen that the reduction in flexural ductility owing to application of axial load is more likely to be critical at a higher degree of reinforcement. Owing to the smaller beneficial effect and the higher likelihood of the adverse effect becoming critical, more careful considera-

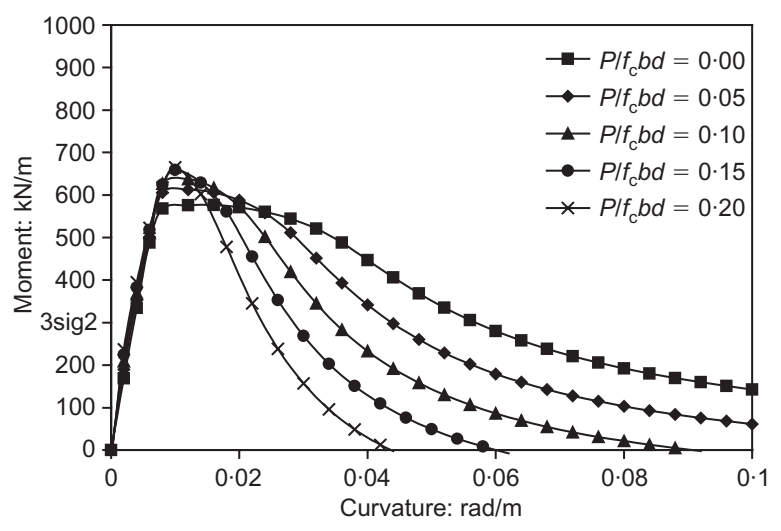

(a) $f_{\mathrm{c}}=30 \mathrm{MPa}, \rho_{\mathrm{t}} / \rho_{\mathrm{bo}}=0 \cdot 5, \rho_{\mathrm{c}}=0$

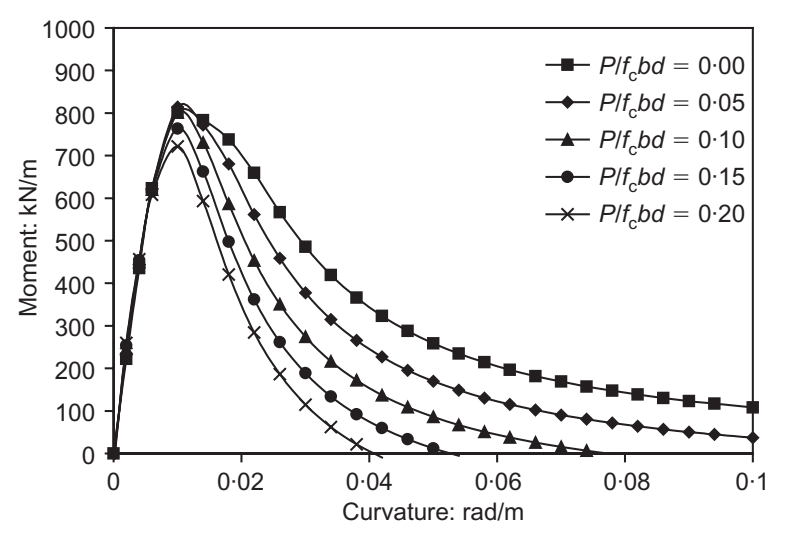

(b) $f_{\mathrm{c}}=30 \mathrm{MPa}, \rho_{\mathrm{t}} / \rho_{\mathrm{bo}}=0.75, \rho_{\mathrm{c}}=0$

Fig. 2. Moment-curvature curves of normal-strength concrete sections

tion of the effects of axial load is needed when the degree of reinforcement is relatively high or, in other words, when the beam is heavily reinforced.

Comparing the moment-curvature curves of sections with $f_{\mathrm{c}}=30 \mathrm{MPa}$ in Fig. 2 with those with $f_{\mathrm{c}}=70 \mathrm{MPa}$ in Fig. 3, it is noted that the adverse effect of axial load on flexural ductility is in general more pronounced at a higher concrete strength. As a result, the reduced flexural ductility is more likely to be critical when HSC is used. Added with the usual provision of heavy reinforcement in conjunction with the use of HSC (so as to increase the flexural strength, which is the main purpose of employing HSC), such adverse effect could render the flexural ductility of a HSC beam unacceptably low. Therefore, although the current practice of ignoring the axial load if it is not too large has been in existence for a long time and so far regarded as satisfactory for beams cast of normal-strength concrete, its applicability to beams cast of HSC needs to be reviewed.

The effect of axial load on moment capacity is better revealed by plotting the relationship between axial load and moment capacity in the form of an interaction diagram, as exemplified by Fig. 4, which depicts such interaction at various values of $\rho_{\mathrm{t}} / \rho_{\mathrm{bo}}$ ranging from 


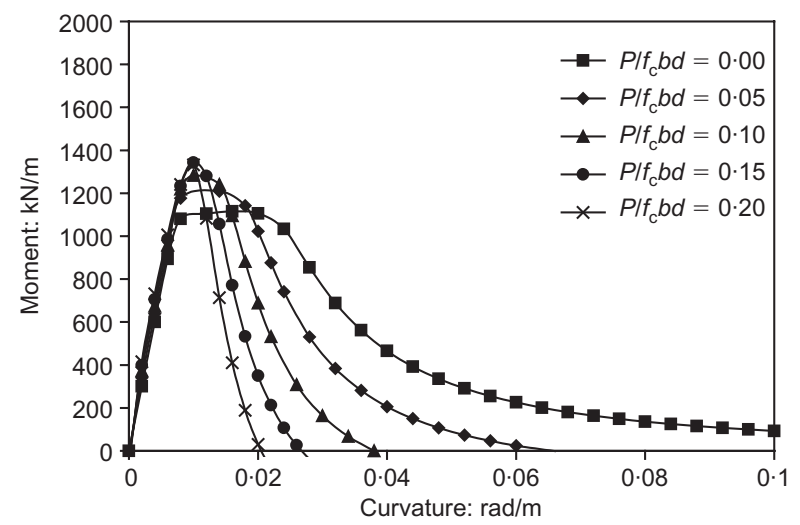

(a) $f_{\mathrm{c}}=70 \mathrm{MPa}, \rho_{\mathrm{t}} / \rho_{\mathrm{bo}}=0.5, \rho_{\mathrm{c}}=0$

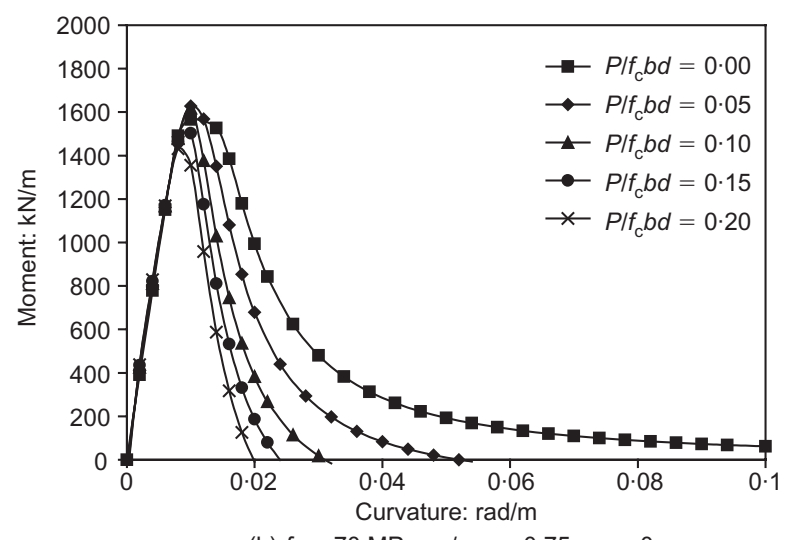

(b) $f_{\mathrm{c}}=70 \mathrm{MPa}, \rho_{\mathrm{t}} / \rho_{\mathrm{bo}}=0 \cdot 75, \rho_{\mathrm{c}}=0$

Fig. 3. Moment-curvature curves of high-strength concrete sections

$0 \cdot 25$ to 1.0 for singly reinforced sections with $f_{\mathrm{c}}=30 \mathrm{MPa}$ and $f_{\mathrm{c}}=70 \mathrm{MPa}$. From this and other similar interaction diagrams obtained for doubly reinforced sections, it is evident that on each interaction curve, there is a turning point giving the maximum moment capacity. In other words, for a given section, there is an axial load (denoted by $P_{\mathrm{o}}$ ) at which the moment capacity of the section reaches a maximum. As the axial load increases from zero, the moment capacity would increase with the axial load until the axial load is equal to $P_{\mathrm{o}}$, beyond which the moment capacity would start to decrease. The axial load levels at these turning points for the case of $\rho_{\mathrm{c}}=0$, expressed in terms of

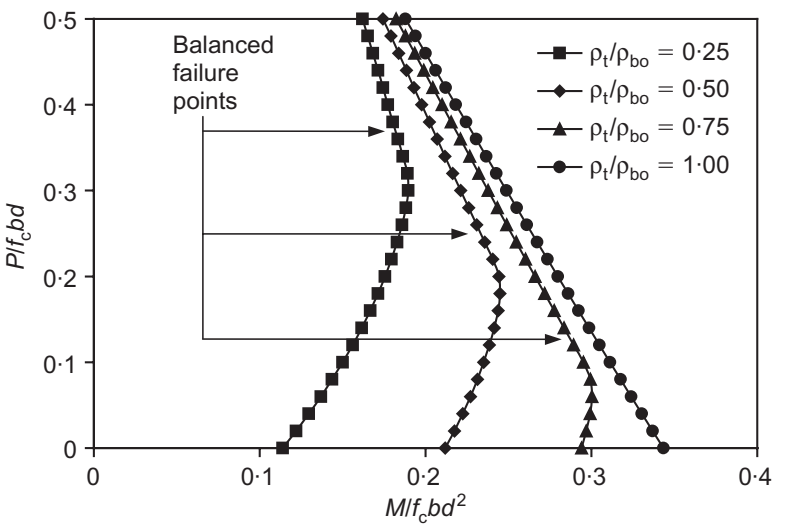

(a) $f_{\mathrm{c}}=30 \mathrm{MPa}, \rho_{\mathrm{c}}=0$

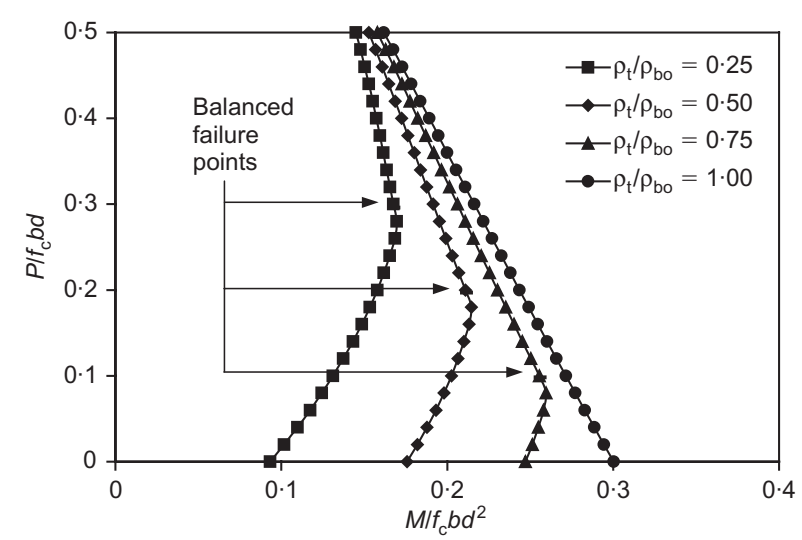

(b) $f_{\mathrm{c}}=70 \mathrm{MPa}, \rho_{\mathrm{c}}=0$

Fig. 4. Axial load-moment interaction diagrams of the sections

$P_{\mathrm{o}} / f_{\mathrm{c}} b d$, are listed in Table 1 . From these results, it can be seen that the axial load level $P_{\mathrm{o}} / f_{\mathrm{c}} b d$ at maximum moment capacity is dependent mainly on the degree of reinforcement, being approximately equal to $0 \cdot 28,0 \cdot 18$ and 0.07 at tension to balanced steel ratios of 0.25 , 0.50 and 0.75 , respectively. It also varies slightly with the concrete compressive strength.

In-depth analysis of the failure modes of the sections revealed that at the turning point of the axial loadmoment interaction curve, that is, at an axial load equal to $P_{\mathrm{o}}$, tension failure (as characterised by yielding of the tension reinforcement before the beam fails) occurs. Above the turning point, there is a point on the inter-

Table 1. Axial loads at maximum moment capacity $\left(\rho_{\mathrm{c}}=0\right)$

\begin{tabular}{|c|c|c|c|c|}
\hline \multirow[t]{2}{*}{$f_{\mathrm{c}}: \mathrm{MPa}$} & \multicolumn{4}{|c|}{ Axial load level at maximum moment capacity, $P_{\mathrm{o}} / f_{\mathrm{c}} b d$} \\
\hline & $\rho_{\mathrm{t}} / \rho_{\mathrm{bo}}=0 \cdot 25$ & $\rho_{\mathrm{t}} / \rho_{\mathrm{bo}}=0 \cdot 50$ & $\rho_{\mathrm{t}} / \rho_{\mathrm{bo}}=0.75$ & $\rho_{\mathrm{t}} / \rho_{\mathrm{bo}}=1.00$ \\
\hline 30 & $0 \cdot 307$ & $0 \cdot 185$ & $0 \cdot 063$ & 0.00 \\
\hline 50 & $0 \cdot 287$ & $0 \cdot 181$ & $0 \cdot 075$ & $0 \cdot 00$ \\
\hline 70 & $0 \cdot 275$ & $0 \cdot 176$ & $0 \cdot 077$ & $0 \cdot 00$ \\
\hline 90 & $0 \cdot 265$ & $0 \cdot 172$ & $0 \cdot 079$ & 0.00 \\
\hline
\end{tabular}


action curve, that is, there is an axial load higher than $P_{\mathrm{o}}$, at which balanced failure (as characterised by the tension reinforcement just reaching the yield stress when the beam fails) occurs. The point at which balanced failure occurs and the corresponding axial load may be called balanced failure point and balanced axial load (denoted by $P_{\mathrm{b}}$ ), respectively. At an axial load higher than $P_{\mathrm{b}}$, compression failure (as characterised by compression failure of the concrete without yielding of the tension reinforcement when the beam fails) occurs. The balanced axial load levels for the case of $\rho_{\mathrm{c}}=0$, expressed in terms of $P_{\mathrm{b}} / f_{\mathrm{c}} b d$, are listed in Table 2 . These results indicate that the balanced axial load level $P_{\mathrm{b}} / f_{\mathrm{c}} b d$ decreases as the tension to balanced steel ratio increases more or less as a linear function and on the whole decreases as the concrete compressive strength increases.

Comparing Table 1 and Table 2, it is obvious that the values of $P_{\mathrm{o}}$ and $P_{\mathrm{b}}$ are not the same. In general, $P_{\mathrm{b}}$ is significantly higher than $P_{\mathrm{o}}$. This can be explained by referring to Fig. 5, in which the variations of the resisting moment $M$, the concrete strain at extreme compression fibre $\varepsilon_{\mathrm{ce}}$ and the tension steel strain $\varepsilon_{\mathrm{st}}$ with the curvature for the section with $f_{\mathrm{c}}=30 \mathrm{MPa}, \rho_{\mathrm{t}} /$ $\rho_{\text {bo }}=0.50$ and $\rho_{\mathrm{c}}=0$ are plotted. Fig. 5(a) is for the case of $P=P_{\mathrm{o}}$ while Fig. 5(b) is for the case of $P=P_{\mathrm{b}}$. It can be seen from the curves plotted that regardless of the applied axial load, the tension steel strain $\varepsilon_{\text {st }}$ increases with the curvature until it reaches a certain maximum value at the post-peak stage and then starts to decrease owing to strain reversal. The maximum tension steel strain and maximum resisting moment do not occur at the same time. From Figs 5(a) and 5(b), it can be read that the tension steel strain at maximum moment when $P=P_{\mathrm{o}}$ is 0.0241 while the tension steel strain at maximum moment when $P=P_{\mathrm{b}}$ is only 0.0213 , which is smaller than the previous value. Since it is the tension steel strain at maximum moment that determines the moment capacity of the section, the moment capacity at $P=P_{\mathrm{b}}$ is smaller than that at $P=P_{\mathrm{o}}$ and consequently $P_{\mathrm{o}} \neq P_{\mathrm{b}}$. The common conception that the moment capacity is largest when balanced failure occurs (i.e. when the axial load is equal to the balanced axial load) is not exactly correct.

Using a trial-and-error process of analysing sections with different tension steel ratios and checking whether

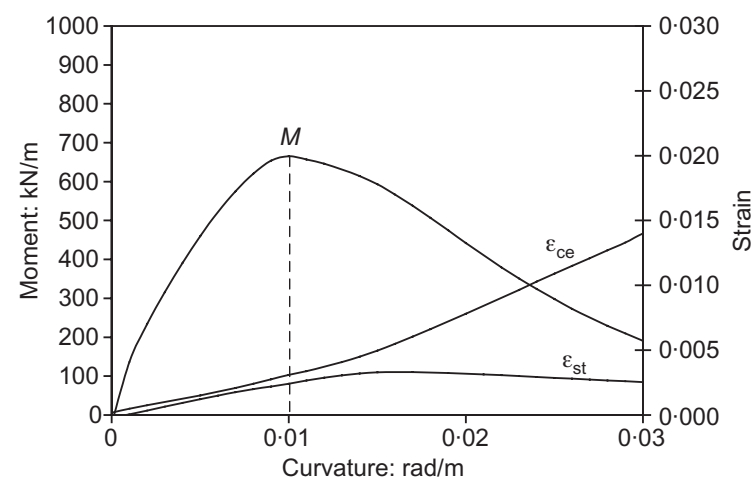

(a) $f_{\mathrm{c}}=30 \mathrm{MPa}, \rho_{\mathrm{t}} / \rho_{\mathrm{bo}}=0.50, \rho_{\mathrm{c}}=0, P=P_{\mathrm{o}}$

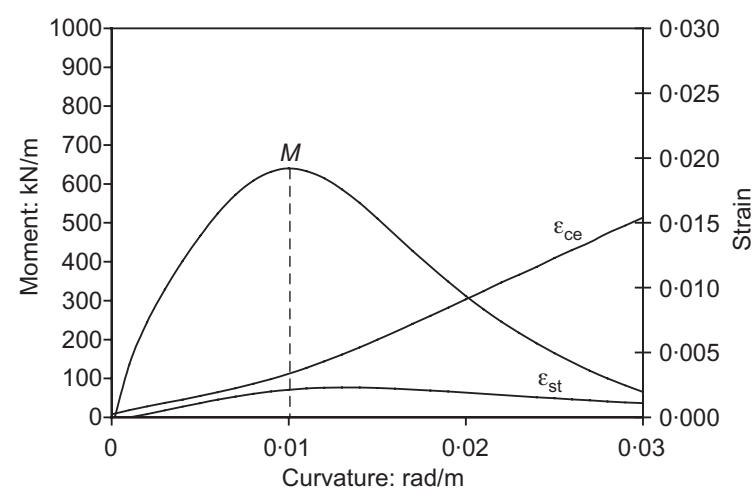

(b) $f_{\mathrm{c}}=30 \mathrm{MPa}, \rho_{\mathrm{t}} / \rho_{\mathrm{bo}}=0.50, \rho_{\mathrm{c}}=0, P=P_{\mathrm{b}}$

Fig. 5. Variations of resisting moment and strains with curvature

the tension steel has yielded before the beam fails, the balanced steel ratios of sections with any given values of $f_{\mathrm{c}}, \rho_{\mathrm{c}}$ and $P / f_{\mathrm{c}} b d$ can be evaluated. The balanced steel ratios so obtained for the case of $\rho_{\mathrm{c}}=0$ are listed in Table 3 , from which it is noted that the balanced steel ratio $\rho_{\mathrm{b}}$ decreases with the axial load level $P / f_{\mathrm{c}} b d$ at a constant rate and on the whole increases significantly as the concrete compressive strength $f_{\mathrm{c}}$ increases. Based on these and other similar results at different values of $\rho_{\mathrm{c}}$, it can be shown that the balanced steel ratio $\rho_{\mathrm{b}}$ of a beam section with compression reinforcement and subjected to axial load is related to the balanced steel ratio $\rho_{\text {bo }}$ of the beam section with no compression reinforcement and no axial load by

Table 2. Balanced axial loads of beam sections $\left(\rho_{\mathrm{c}}=0\right)$

\begin{tabular}{|c|c|c|c|c|}
\hline \multirow[t]{2}{*}{$f_{\mathrm{c}}: \mathrm{MPa}$} & \multicolumn{4}{|c|}{ Balanced axial load level, $P_{\mathrm{b}} / f_{\mathrm{c}} b d$} \\
\hline & $\rho_{\mathrm{t}} / \rho_{\mathrm{bo}}=0 \cdot 25$ & $\rho_{\mathrm{t}} / \rho_{\mathrm{bo}}=0 \cdot 50$ & $\rho_{\mathrm{t}} / \rho_{\mathrm{bo}}=0.75$ & $\rho_{\mathrm{t}} / \rho_{\mathrm{bo}}=1.00$ \\
\hline $\begin{array}{l}30 \\
50 \\
70 \\
90\end{array}$ & $\begin{array}{l}0 \cdot 365 \\
0 \cdot 321 \\
0 \cdot 296 \\
0 \cdot 277\end{array}$ & $\begin{array}{l}0 \cdot 243 \\
0 \cdot 214 \\
0 \cdot 197 \\
0 \cdot 185\end{array}$ & $\begin{array}{l}0.121 \\
0 \cdot 107 \\
0.098 \\
0.092\end{array}$ & $\begin{array}{l}0 \cdot 00 \\
0 \cdot 00 \\
0 \cdot 00 \\
0 \cdot 00\end{array}$ \\
\hline
\end{tabular}


Table 3. Balanced steel ratios of beam sections $\left(\rho_{\mathrm{c}}=0\right)$

\begin{tabular}{l|c|c|c|c|c}
\hline \multirow{2}{*}{$f_{\mathrm{c}}: \mathrm{MPa}$} & \multicolumn{5}{|c}{ Balanced steel ratio, $\rho_{\mathrm{b}}: \%$} \\
\cline { 2 - 6 } & $P / f_{\mathrm{c}} b d=0$ & $P / f_{\mathrm{c}} b d=0 \cdot 05$ & $P / f_{\mathrm{c}} b d=0 \cdot 10$ & $P / f_{\mathrm{c}} b d=0 \cdot 15$ & $P / f_{\mathrm{c}} b d=0 \cdot 20$ \\
\hline 30 & $3 \cdot 18$ & $2 \cdot 85$ & $2 \cdot 52$ & $2 \cdot 20$ & $1 \cdot 87$ \\
50 & $4 \cdot 66$ & $4 \cdot 12$ & 3.58 & 3.03 & 2.49 \\
70 & $6 \cdot 02$ & $5 \cdot 25$ & 4.49 & 3.73 & $2 \cdot 97$ \\
90 & $7 \cdot 24$ & $6 \cdot 27$ & $5 \cdot 29$ & $4 \cdot 31$ & 3.33 \\
\hline
\end{tabular}

$$
\rho_{\mathrm{b}}=\rho_{\mathrm{bo}}+\rho_{\mathrm{c}}-\frac{P}{f_{\mathrm{yt}} b d}
$$

Balanced failure occurs when the tension steel ratio $\rho_{\mathrm{t}}$ is equal to the balanced steel ratio $\rho_{\mathrm{b}}$, that is

$$
\rho_{\mathrm{t}}=\rho_{\mathrm{bo}}+\rho_{\mathrm{c}}-\frac{P}{f_{\mathrm{yt}} b d}
$$

Since the applied axial load when balanced failure occurs is actually the balanced axial load, the above equation may be expressed in the following form

$$
\rho_{\mathrm{t}}=\rho_{\mathrm{bo}}+\rho_{\mathrm{c}}-\frac{P_{\mathrm{b}}}{f_{\mathrm{yt}} b d}
$$

from which the balanced axial load level $P_{\mathrm{b}} / f_{\mathrm{c}} b d$ may be obtained as

$$
\frac{P_{\mathrm{b}}}{f_{\mathrm{c}} b d}=\left(\rho_{\mathrm{bo}}+\rho_{\mathrm{c}}-\rho_{\mathrm{t}}\right)\left(f_{\mathrm{yt}} / f_{\mathrm{c}}\right)
$$

It can be verified that the values of $P_{\mathrm{b}} / f_{\mathrm{c}} b d$ presented in Table 2 agree almost exactly with the above formula so derived. This formula clearly shows how the balanced axial load level $P_{\mathrm{b}} / f_{\mathrm{c}} b d$ varies with the balanced steel ratio $\rho_{\text {bo }}$, the tension steel ratio $\rho_{\mathrm{t}}$, the compression steel ratio $\rho_{\mathrm{c}}$, the steel yield strength $f_{\mathrm{yt}}$ and the concrete compressive strength $f_{\mathrm{c}}$. In actual design practice, it is more convenient to use this formula than to use the tabulated values given in Table 2, especially if the design procedure is to be computerised.

\section{Ductility analysis}

From the moment-curvature curves, the flexural ductility of the sections can be evaluated in terms of a curvature ductility factor $\mu$, given by

$$
\mu=\phi_{\mathrm{u}} / \phi_{\mathrm{y}}
$$

where $\phi_{\mathrm{u}}$ and $\phi_{\mathrm{y}}$ are the ultimate curvature and yield curvature respectively. The ultimate curvature is defined as the curvature of the section when its resisting moment, having reached the peak, drops to $80 \%$ of the peak moment. The yield curvature is taken as that at the hypothetical yield point of an equivalent linearly elastic perfectly plastic system with an elastic stiffness equal to the secant stiffness of the section at 0.75 of the peak moment and a yield moment equal to the peak moment.

The curvature ductility factors so obtained for singly reinforced sections are plotted against the tension to balanced steel ratios in Fig. 6. Only the numerical results at concrete compressive strength of $f_{\mathrm{c}}=30 \mathrm{MPa}$ and $f_{\mathrm{c}}=70 \mathrm{MPa}$ are presented because the results at other concrete compressive strength are similar. As has been shown before, ${ }^{8-10}$ the ductility factor $\mu$ decreases as the tension to balanced steel ratio $\rho_{\mathrm{t}} / \rho_{\text {bo }}$ increases and is generally lower at a higher concrete compressive strength $f_{\mathrm{c}}$. Application of any axial load up to the range of axial load level covered in the study (i. e. up to an axial load level of $\left.P / f_{\mathrm{c}} b d=0.5\right)$ does not change

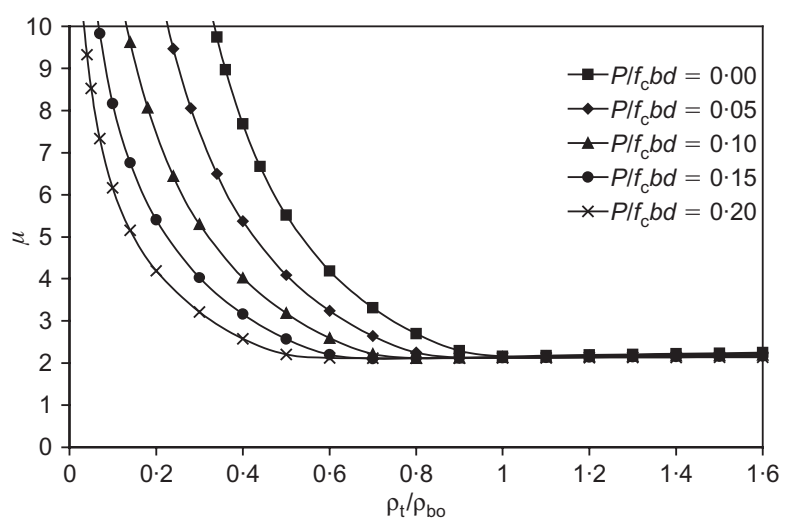

(a) $f_{\mathrm{c}}=30 \mathrm{MPa}, \rho_{\mathrm{c}}=0$

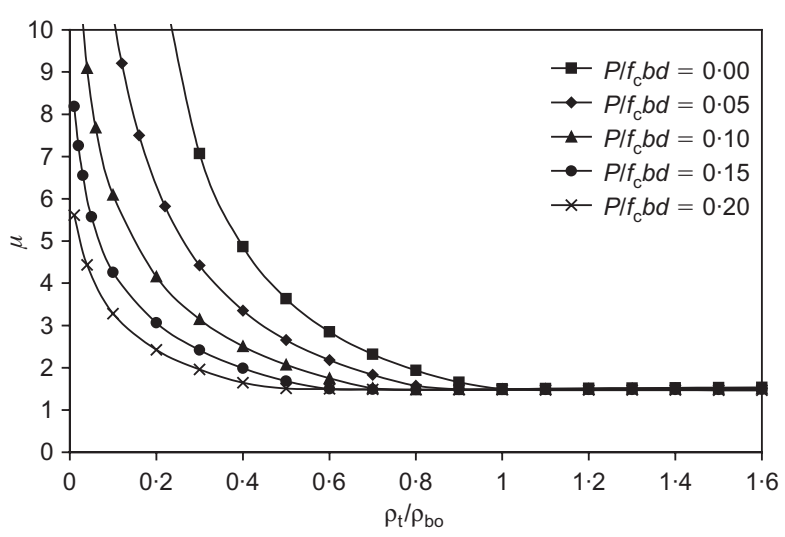

(a) $f_{\mathrm{c}}=70 \mathrm{MPa}, \rho_{\mathrm{c}}=0$

Fig. 6. $\mu$ of singly reinforced sections plotted against $\rho_{\mathrm{t}} / \rho_{\mathrm{bo}}$

Magazine of Concrete Research, 2006, 58, No. 6 
this general trend of decreasing ductility factor with increasing tension to balanced steel ratio and/or concrete compressive strength. Comparing the $\mu$ versus $\rho_{\mathrm{t}} / \rho_{\text {bo }}$ curves at different axial load levels, it is evident that for a given section, the application of axial load significantly reduces the ductility factor. For example, when the axial load level $P / f_{\mathrm{c}} b d$ is increased from 0 to $0 \cdot 1$, the ductility factor $\mu$ at $\rho_{\mathrm{t}} / \rho_{\text {bo }}=0.5$ and $f_{\mathrm{c}}=30 \mathrm{MPa}$ decreases from 5.5 to 3.2 while the ductility factor $\mu$ at $\rho_{\mathrm{t}} / \rho_{\text {bo }}=0.5$ and $f_{\mathrm{c}}=70 \mathrm{MPa}$ decreases from 3.6 to $2 \cdot 1$. At a higher tension to balanced steel ratio, the reduction in ductility factor owing to application of axial load is smaller but because of the relatively low ductility, the reduction in ductility is more likely to be critical, especially when HSC is used.

In previous studies ${ }^{8,9}$ the first author's research group has shown that the major factor determining the flexural ductility of a singly or doubly reinforced beam section is the degree of reinforcement $\lambda$, which may be measured in terms of the tension steel ratio $\rho_{\mathrm{t}}$, the compression steel ratio $\rho_{\mathrm{c}}$ and the balanced steel ratio with no compression reinforcement $\rho_{\text {bo }}$, as given by the following equation

$$
\lambda=\left(\rho_{\mathrm{t}}-\rho_{\mathrm{c}}\right) / \rho_{\mathrm{bo}}
$$

When $\lambda<1, \lambda=1$ and $\lambda>1$, the section would fail by tension, balanced and compression failure, respectively. Extensive parametric studies ${ }^{8,9}$ have yielded the following formula for direct estimation of the ductility factor $\mu$

$$
\mu=10 \cdot 7 f_{\mathrm{c}}^{-0 \cdot 45} \lambda^{-1 \cdot 25}
$$

in which all strengths are in MPa and $\lambda$ should be taken as $1 \cdot 0$ when $\lambda>1$.

For the purpose of incorporating the effect of axial load on flexural ductility, it is proposed to redefine the degree of reinforcement $\lambda$ as

$$
\lambda=\left(\rho_{\mathrm{t}}-\rho_{\mathrm{c}}+\frac{P}{f_{\mathrm{yt}} b d}\right) / \rho_{\mathrm{bo}}
$$

As before, when $\lambda<1, \lambda=1$ and $\lambda>1$, the section would fail by tension, balanced and compression failure, respectively. The $\mu$ values shown in Figs 6 and 7 are re-plotted against the $\lambda$ values in Fig. 8 . It is found that the different $\mu$ versus $\lambda$ curves at various axial load levels and compression steel ratios are very close to each other, especially when $\lambda>0 \cdot 6$. Hence, a reasonably accurate and conservative estimate of the ductility factor $\mu$ may be obtained using just the lowest $\mu$ versus $\lambda$ curve, that is, the one corresponding to the case of no axial load. The equation of this $\mu$ versus $\lambda$ curve is the same as equation (7).

From the above analysis, it may be concluded that the applied axial load causes reduction in flexural ductility mainly through the increase in degree of reinforcement. Hence, the adverse effect of axial load on

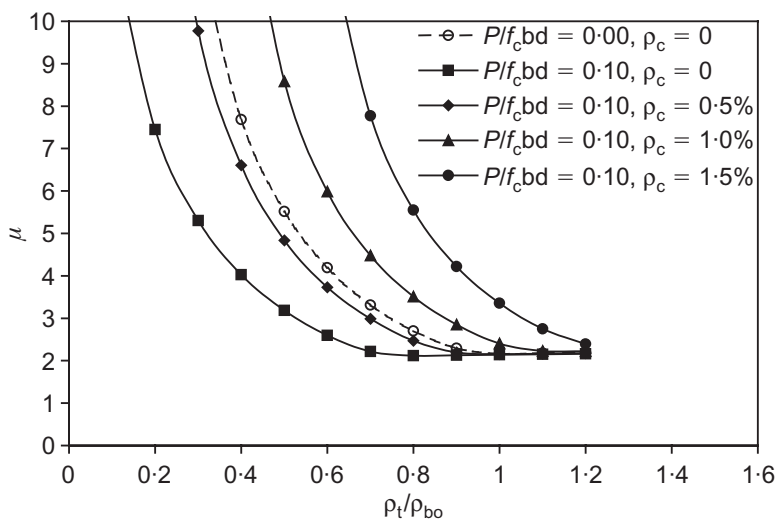

(a) $f_{\mathrm{c}}=30 \mathrm{MPa}, \rho_{\mathrm{c}} \neq 0$

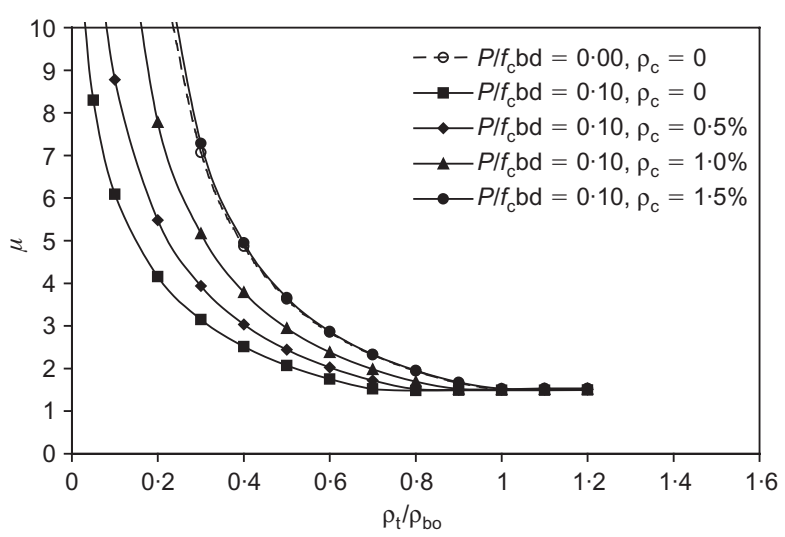

(b) $f_{\mathrm{c}}=70 \mathrm{MPa}, \rho_{\mathrm{c}} \neq 0$

Fig. 7. $\mu$ of doubly reinforced sections plotted against $\rho_{\mathrm{t}} / \rho_{\mathrm{bo}}$

flexural ductility may be controlled by limiting the degree of reinforcement.

\section{Design of beams subjected to small axial loads}

The effects of the applied axial load may be neglected if the following conditions are satisfied: $(a)$ there is no reduction in flexural strength and $(b)$ the reduced flexural ductility is still higher than a certain minimum required level. Otherwise, the effects on both flexural strength and flexural ductility should be fully considered in the design.

Since the moment capacity increases with the axial load until $P=P_{\mathrm{o}}$, the moment capacity would actually become larger when an axial load not higher than $P_{\mathrm{o}}$ is applied. The moment capacity would start to decrease when the axial load is higher than $P_{\mathrm{o}}$ but would remain larger than that with no axial load applied until the axial load is excessively high. The numerical results obtained in the present study revealed that in general, or at least within the ranges of parameters covered in the study, even when the axial load is increased to $P_{\mathrm{b}}$, which is higher than $P_{\mathrm{o}}$, the moment capacity would remain larger than that with no axial load applied. 

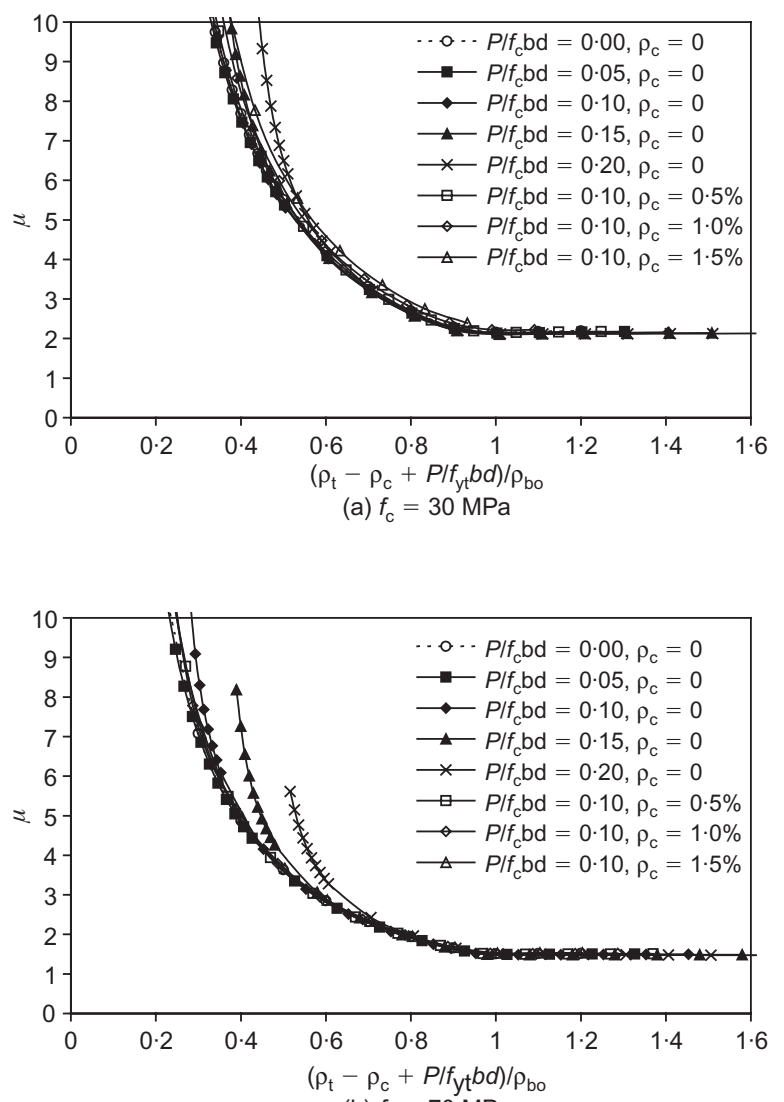

(b) $f_{\mathrm{c}}=70 \mathrm{MPa}$

Fig. 8. $\mu$ of singly and doubly reinforced sections plotted against $\left(\rho_{\mathrm{t}}-\rho_{\mathrm{c}}+P / f_{\mathrm{yt}} b d\right) / \rho$

Hence, there should be no reduction in flexural strength provided the axial load applied is not higher than the balanced axial load, which may be evaluated using equation (4). It is therefore recommended to set a limit to the applied axial load as

$$
\frac{P}{f_{\mathrm{c}} b d} \leqslant\left(\rho_{\mathrm{bo}}+\rho_{\mathrm{c}}-\rho_{\mathrm{t}}\right)\left(f_{\mathrm{yt}} / f_{\mathrm{c}}\right)
$$

Based on similar studies, a minimum flexural ductility design method for both normal- and high-strength concrete beams has been developed previously by the first author's research group. ${ }^{10}$ The basic principle behind this design method is that in order to provide a consistent level of minimum flexural ductility, a fixed minimum value for the curvature ductility factor should be set. The minimum required curvature ductility factor (denoted by $\mu_{\min }$ ) may be established by referring to the curvature ductility factors being provided in the various existing codes for normal-strength concrete beams (the provisions in the existing codes are largely developed from experience with traditional materials like normal-strength concrete). After surveying the various existing codes, a minimum curvature ductility factor of $\mu_{\min }=3.32$ has been recommended. However, if considered necessary, a higher value of $\mu_{\text {min }}$ may be adopted. Setting this minimum limit $\mu_{\min }$ to the re- duced flexural ductility, which may be evaluated using equation (7), the maximum limit $\lambda_{\max }$ that should be applied to the degree of reinforcement can be obtained by solving the following equation

$$
\mu_{\min }=10 \cdot 7 f_{\mathrm{c}}^{-0 \cdot 45} \lambda_{\max }^{-1 \cdot 25}
$$

from which the maximum limit $\lambda_{\max }$ is derived as

$$
\lambda_{\max }=6 \cdot 66 f_{\mathrm{c}}^{-0.36} \mu_{\min }^{-0 \cdot 8}
$$

Substituting this maximum limit into equation (8), the corresponding limit to be set to the applied axial load is obtained as

$$
\frac{P}{f_{\mathrm{c}} b d} \leqslant\left(\lambda_{\max } \rho_{\mathrm{bo}}+\rho_{\mathrm{c}}-\rho_{\mathrm{t}}\right)\left(f_{\mathrm{yt}} / f_{\mathrm{c}}\right)
$$

Summing up the above flexural strength and flexural ductility considerations, the condition that there is no reduction in flexural strength leads to equation (9) while the condition that the reduced flexural ductility is still higher than a certain minimum required level leads to equation (12). Since $\lambda_{\max }$ is in general smaller than $1 \cdot 0$, the limit set by equation (12) is always smaller than that set by equation (9) and therefore equation (12) would govern. In other words, the flexural ductility consideration would control the design of beams subjected to small axial loads. The axial load level limit imposed by equation (12) decreases with both the degree of reinforcement and the concrete compressive strength. This is in line with the general observation that the reduction in flexural ductility owing to application of axial load is more likely to be critical in heavily reinforced sections and/or sections cast of HSC.

When the degree of reinforcement is relatively low and normal-strength concrete is used, there should be no particular difficulties in meeting the axial load limit requirement. However, when the degree of reinforcement is relatively high and/or HSC is used, it may be difficult to meet the axial load limit requirement. This problem may be dealt with in the following ways: $(a)$ increase the section size so that the degree of reinforcement and the axial load level are reduced and $(b)$ increase the compression steel ratio so that the degree of reinforcement is reduced. Increasing the section size would increase the dead weight and affect the general layout of the structure. Comparatively, the alternative of putting in more compression steel until equation (12) is satisfied would seem to be a simpler and better solution. The amount of compression steel needed increases with the concrete compressive strength but is generally smaller than that required to carry the whole of the applied axial load.

Based on the above, the following design guidelines are developed.

(a) If the applied axial load is larger than $10 \%$ of the axial load capacity of the concrete section, the member should be designed as a column.

(b) If the applied axial load is smaller than or equal to 
$10 \%$ of the axial load capacity of the concrete section, the member may be designed as a beam provided the axial load level limit imposed by equation (12) is satisfied.

(c) The effects of axial load are generally more significant at a higher degree of reinforcement and/or a higher concrete compressive strength. Thus, particular care is needed to cater for the effects of axial load when the beam is heavily reinforced and/or cast of high-strength concrete.

(d) If necessary, the axial load level limit imposed by equation (12) may be satisfied by increasing the section size or putting in more compression steel.

\section{Conclusions}

A comprehensive parametric study based on theoretical analysis has been carried out to investigate the effects of axial load on the complete moment-curvature behaviour of normal- and high-strength concrete beams with different degrees of reinforcement. The study led to the following conclusions and design guidelines for beams subjected to small axial loads.

(a) As the axial load increases from zero, the moment capacity would increase with the axial load and reach a maximum when the axial load is equal to a certain value (denoted by $P_{\mathrm{o}}$ ) beyond which the moment capacity would start to decrease but would remain larger than that with no axial load applied even when the axial load is increased to the balanced axial load (denoted by $P_{\mathrm{b}}$ ). At $P_{\mathrm{o}}$, tension failure would occur while at $P_{\mathrm{b}}$, balanced failure would occur. Provided the axial load is not larger than the balanced axial load, there should be no reduction in flexural strength owing to the application of axial load.

(b) No matter how small the axial load is, the flexural ductility would always decrease upon the application of an axial load. The reduction in flexural ductility is generally more serious when the beam section is heavily reinforced and/or cast of highstrength concrete. Correlation of the ductility factors of the beam sections analysed to the degrees of reinforcement revealed that the applied axial load causes reduction in flexural ductility mainly through the increase in degree of reinforcement. To incorporate such effects, a new measure of degree of reinforcement has been developed.

(c) Based on the numerical results obtained, formulae for the evaluation of the balanced axial load, degree of reinforcement and ductility factor of a beam section subjected to a small axial load have been derived, as given by equations (4), (8) and (7), respectively.

(d) When designing beams subjected to axial loads, the conditions that there should be no reduction in flexural strength and that the reduced flexural ductility is still higher than the minimum required level must be satisfied. Between these two conditions, the latter one would govern because it imposes a lower limit to the axial load level. A formula for the evaluation of this axial load limit has been derived, as given by equation (12).

\section{References}

1. American Concrete Institute. Building Code Requirements for Structural Concrete and Commentary. American Concrete Institute, Farmington Hills, USA, 1999, ACI 318-99 and ACI 318R-99.

2. American Concrete Institute. Building Code Requirements for Structural Concrete and Commentary. American Concrete Institute, Farmington Hills, USA, 2002, ACI 318-02 and ACI 318R-02.

3. Standards Australia International. Australian Standard: Concrete Structures. Standards Australia International, Sydney, Australia, 1994, AS 3600-1994.

4. British Standards Institution. BS 8110: Part 1: 1997, Structural Use of Concrete, Code of Practice for Design and Construction. BSI, London, UK, 1997.

5. BayraK O. and SheikH S. A. High-strength concrete columns under simulated earthquake loading. ACI Structural Journal, 1997, 94, No. 6, 708-722.

6. LÉGeron F. and PAultre P. Behavior of high-strength concrete columns under cyclic flexure and constant axial load. ACI Structural Journal, 2000, 97, No. 4, 591-601.

7. Ho J. C. M. and РАM H. J. Inelastic design of low-axially loaded high-strength reinforced concrete columns. Engineering Structures, 2003, 25, No. 8, 1083-1096.

8. Pam H. J., Kwan A. K. H. and Ho J. C. M. Post-peak behavior and flexural ductility of doubly reinforced normal- and highstrength concrete beams. Structural Engineering and Mechanics, 2001, 12, No. 5, 459-474.

9. Ho J. C. M., Kwan A. K. H. and PAM H. J. Theoretical analysis of post-peak flexural behavior of normal- and high-strength concrete beams. Structural Design of Tall and Special Buildings, 2003, 12, No. 2, 109-125.

10. Ho J. C. M., Kwan A. K. H. and PAM H. J. Minimum flexural ductility design of high-strength concrete beams. Magazine of Concrete Research, 2004, 56, No. 1, 13-22.

11. Attard M. M. and Setunge S. The stress strain relationship of confined and unconfined concrete. ACI Materials Journal, 1996, 93, No. 5, 432-444.

12. Attard M. M. and Stewart M. G. A two parameter stress block for high-strength concrete. ACI Structural Journal, 1998, 95, No. 3, 305-317.

Discussion contributions on this paper should reach the editor by 1 February 2007 